\title{
Respiratory Water Loss: A Predictive Model
}

\author{
WILLIAM R. WELCH \\ Department of Zoology, University of Wisconsin, \\ Madison, Wisconsin 53706, U.S.A. \\ C. Richard TRacy \\ Department of Zoology and Entomology, Colorado State University, \\ Fort Collins, Colorado 80523, U.S.A. \\ and \\ University of Michigan, Biological Station, \\ Douglas Lake, Pellston, Michigan 49769, U.S.A. \\ (Received 18 April 1975, and in revised form 3 May 1976)

\begin{abstract}
A steady-state model, based on a combination of empirical and mechanistic relationships, is developed to predict respiratory water loss from terrestrial vertebrates. Model parameters are evaluated from published data for the banner-tail kangaroo rat (Dipodomys spectabilis). A threedimensional representation of model behavior is presented, emphasizing the interaction of organismal and environmental variables. The model makes possible the calculation of respiratory water and heat losses for animals in both artificial and natural environments.
\end{abstract}

\section{Introduction}

The exchange of water and/or energy as a result of evaporation from respiratory surfaces can be of considerable consequence to terrestrial organisms. It may, in part, determine many animals' abilities to exist in certain physical environments, and/or to optimize physiological and behavioral responses with those environments.

Collins, Pilkington \& Schmidt-Nielsen (1971) modeled heat exchange in mammalian nasal passages with the assumption that respiratory processes can be approximated as constant or steady-state air, water vapor and heat flows. Their model, however, requires the temperature of expired air as an input variable. This requirement may be an unnecessary constraint on 
biologists (especially ecologists) who often must predict respiratory water and heat losses only from an organism's physical environments.

In this paper we present a model which, after evaluation of appropriate animal parameters, permits calculation of respiratory water loss solely from environmental variables. The model is applicable to terrestrial vertebrates under any environmental conditions.

\section{Model Formulation}

We have developed a set of equations, based on physiological parameters and the water vapor density of inspired air, that constitute a steady-state model for respiratory evaporation. All symbols in the equations are defined in Appendix A.

The principal equation of the model describes respiratory water loss $\left(\dot{m}_{R}\right)$ as the product of respiratory ventilation $(\dot{V})$ and the difference between expired $\left(\rho_{E}\right)$ and inspired $\left(\rho_{I}\right)$ water vapor densities so that

$$
\dot{m}_{R}=\dot{V}\left[\left(\rho_{E} / \alpha\right)-\rho_{I}\right] \text {. }
$$

Equation (1) is derived in Appendix B.

Respiratory ventilation often is computed from respiratory mechanics as the product of breathing frequency $(f)$ and tidal volume $\left(V_{T}\right)$ so that

$$
\dot{V}=f V_{T} / m \text {. }
$$

Alternatively, respiratory ventilation can be related to oxygen consumption $\left(\dot{V}_{2}\right)$, oxygen extraction coefficient $(E)$, and fraction of oxygen in inspired air $\left(F_{I} \mathrm{O}_{2}\right)$ as

$$
\dot{V}=\dot{V} \mathrm{O}_{2} /\left(\beta E F_{1} \mathrm{O}_{2}\right) \text {. }
$$

This equation is fully derived in Appendix $\mathrm{C}$.

Equations (1) and (3) are used to relate the environmental and organismal variables that determine respiratory water loss in the model presented here.

\section{Model Parameters}

Some of the terms in equations (1) and (3) (viz. $\rho_{E}$ and $E$ ) are not environmental variables, yet they are related to environmental or organismal variables. Such relationships among variables can be formalized by regression analysis. We have established relationships between extraction coefficient and oxygen consumption, and the water vapor density of expired air and the water vapor density and temperature of inspired air. 


\section{(A) OXYGEN EXTRACTION COEFFICIENT}

Under conditions in which respiration is related primarily to oxygen consumption (rather than panting), the extraction of oxygen from inspired air appears to be related to oxygen consumption and/or body temperature. Joyce \& Blaxter (1964), for example, have shown a positive relationship between the difference in concentration of oxygen in expired and inspired air (i.e. oxygen extraction) and oxygen consumption by sheep. Taylor (1969), however, has shown that oxygen extraction, for two species of ungulates, varies inversely with body temperature. He also contends that an increase in oxygen extraction is a normal accompaniment to cold exposure.

Scrutiny of Joyce \& Blaxter's data (their Fig. 2) shows that the relationship between oxygen extraction and oxygen consumption is linear at temperatures below thermal neutrality, and highly variable regardless of a constant oxygen consumption within the range of thermal neutrality. Furthermore, Bernstein \& Schmidt-Nielsen (1974) have shown that oxygen extraction by crows at temperatures above thermal neutrality is somewhat higher than below the upper critical temperature.

In the light of the above information, we conclude that oxygen extraction may be expressed as a linear function of oxygen consumption for animals at temperatures below their thermal neutral zone. We caution that this conclusion is based on little existing data, and that elaboration of the relationship between oxygen extraction and oxygen consumption should be an important area of future research.

We have used equation (3) and data from Collins et al. (1971, Table II) to calculate extraction coefficients for the banner-tail kangaroo rat (Dipodomys spectabilis). These extraction coefficients are related to oxygen consumption in Fig. 1, showing a linear correlation that may extend even into the thermal neutral zone. The data from Collins et al. (1971) do not permit calculation of extraction coefficients at temperatures above thermal neutrality, where the animal may hyperventilate to enhance respiratory water loss. Nevertheless, provided that the appropriate data for an organism are available, we see no reason why such extraction coefficients cannot be similarly determined. With the caution that the same relationship in Fig. 1 may not hold for animals at temperatures in or above thermal neutrality (we also suspect that this relationship may not be adequate for strenuously exercising animals), we propose that the oxygen extraction coefficient $(E)$ is related to oxygen consumption $\left(\dot{V} \mathrm{O}_{2}\right)$ by the linear regression

$$
E=k_{1}+\left(k_{2} \dot{V_{2}}\right)
$$




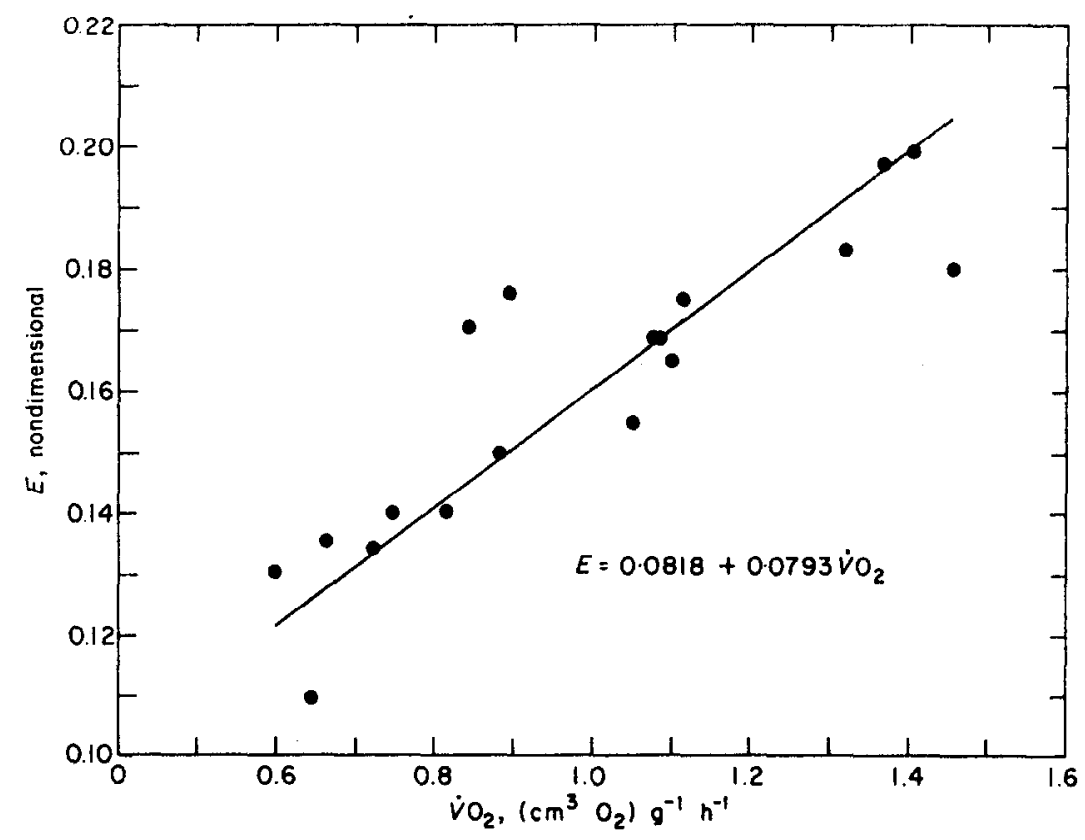

FIG. 1. Extraction coefficient $(E)$ as a function of oxygen consumption $\left(\dot{V}_{2}\right)$ for the banner-tail kangaroo rat (Dipodomys spectabilis). Extraction coefficients were calculated with equation (3) using data from Collins et al. (1971, Table II). The straight line was fit to the data by linear regression [equation (4)].

\section{(B) WATER VAPOR DENSITY OF EXPIRED AIR}

The water vapor density of expired air can be determined by assuming that the air is saturated with water at the temperature of expired air (SchmidtNielsen, 1972). For several animals, the temperature of expired air (nasal temperature) is known to be linearly related to the temperature of inspired air (Jackson \& Schmidt-Nielsen, 1964; Getz, 1968; Murrish \& SchmidtNielsen, 1970; Schmidt-Nielsen, Hainsworth \& Murrish, 1970; Murrish, 1973; Hulbert \& Dawson, 1974), and to be influenced by ambient relative humidity (McCutchan \& Taylor, 1951; Jackson \& Schmidt-Nielsen, 1964; Collins et al., 1971). It follows from this empirical evidence that the water vapor density of expired air should be related to the water vapor density of inspired air. Figure 2 shows such a relationship for examples from three classes of vertebrates.

The exchanges of heat at the nasal surfaces simultaneously determine the temperature and water vapor density of expired air. The mechanisms of heat exchange at these nasal surfaces feature convection and evaporation as the primary modes of heat transfer (Collins et al., 1971; Seymour, 1972). This 


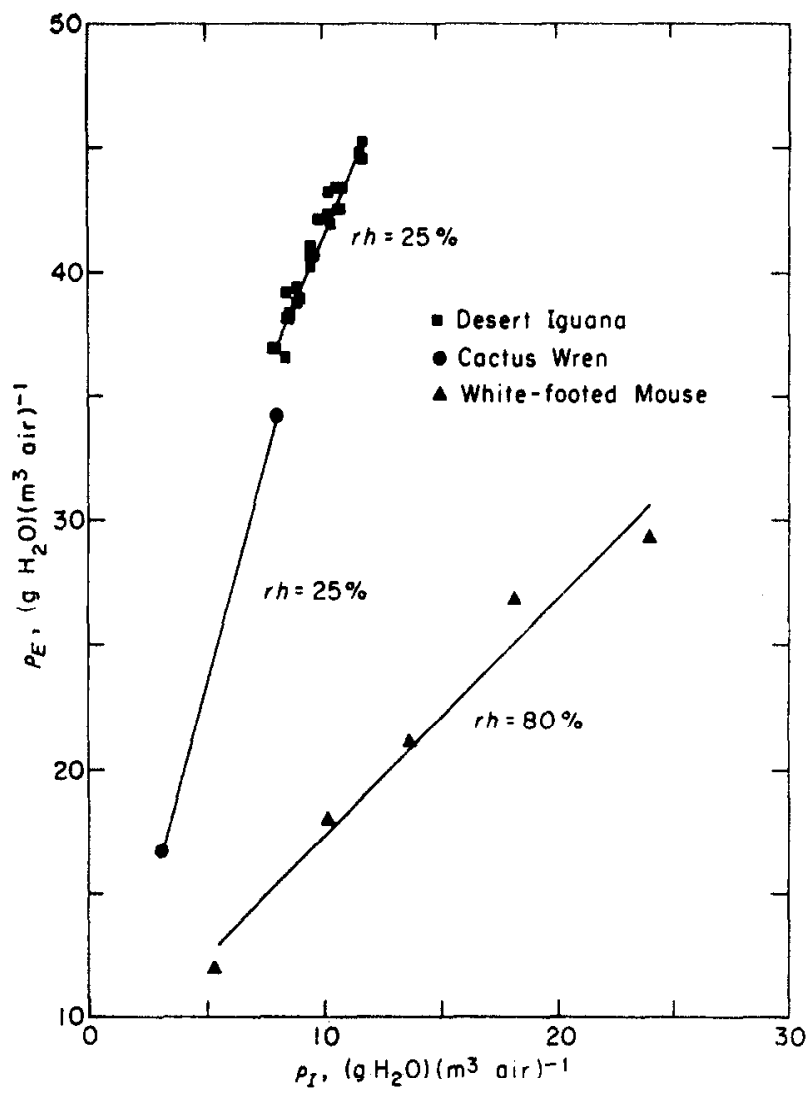

Fig. 2. Water vapor density of expired air $\left(\rho_{E}\right)$ as a function of water vapor density of inspired (ambient) air $\left(\rho_{l}\right)$ for three classes of vertebrates. Data for the desert iguana (Dipsosaurus dorsalis) from Murrish \& Schmidt-Nielsen (1970, Fig. 2); for the cactus wren (Campylorhynchus brunneicapillum) from Schmidt-Nielsen et al. (1970, Fig. 3); for the white-footed mouse (Peromyscus leucopus) from Getz (1968, Table I).

implies that both the temperature $\left(T_{I}\right)$ and relative humidity $(r h)$ of inspired air (and thus $\rho_{l}$ ) are important in determining the water vapor density of expired air $\left(\rho_{E}\right)$. We have illustrated this relationship for kangaroo rats in Fig. 3. This relationship appears to be adequately expressed by multiple linear regression as

$$
\rho_{E}=k_{3}+\left(k_{4} \rho_{I}\right)+\left(k_{5} T_{I}\right) \text {. }
$$

In the experiments represented by Fig. 2 , differences in water vapor density of inspired air were created solely from manipulation of air temperature while maintaining constant relative humidities. In Fig. 3, differences in water vapor density were produced by manipulation of both inspired air 


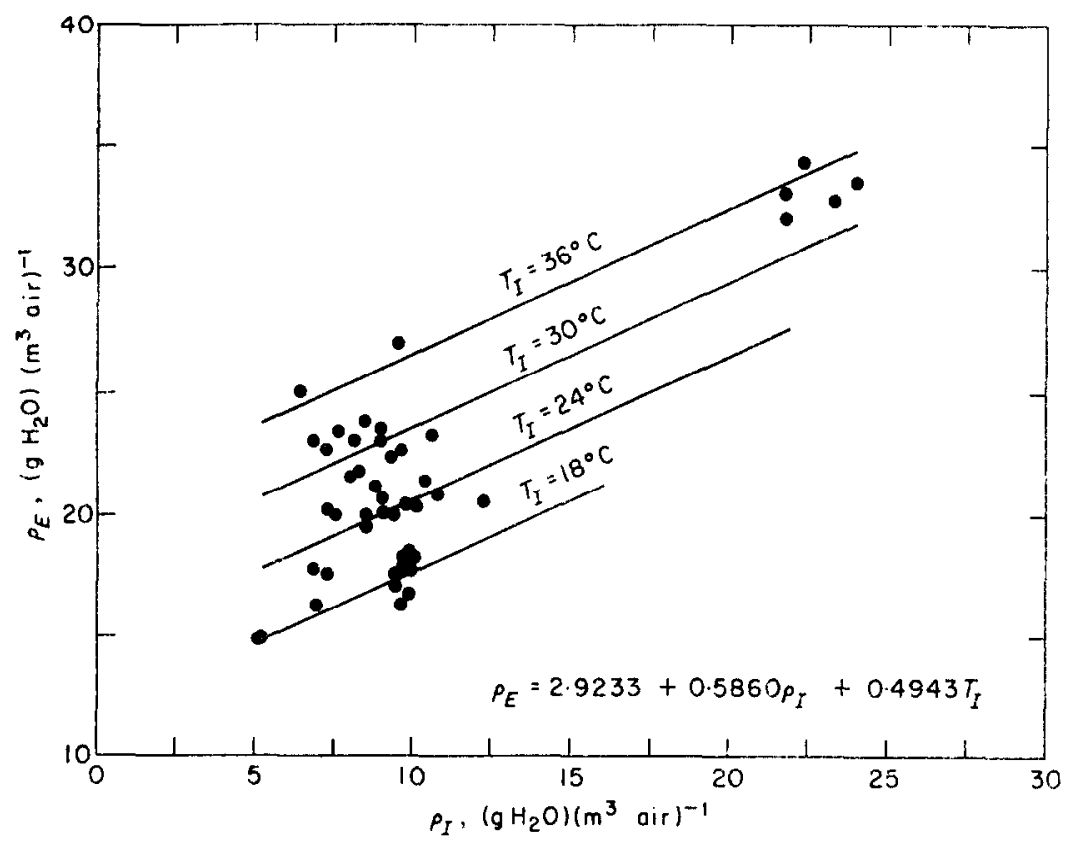

FIG. 3. Water vapor density of expired air $\left(\rho_{E}\right)$ as a function of water vapor density of inspired (ambient) air $\left(\rho_{I}\right)$ for the banner-tail kangaroo rat (Dipodomys spectabilis). Water vapor densities were calculated with temperature and humidity data from Collins et al. (1971, Tables III and IV). The data are described by a multiple linear regression [equation (5)], which is exemplified by lines at the indicated temperatures.

temperature and humidity; thus this figure more completely describes the relationship between the water vapor density of inspired and expired air.

In the foregoing, we used published data for $\dot{V}, \dot{V} \mathrm{O}_{2}, F_{I} \mathrm{O}_{2}, \rho_{I}$ and $T_{E}$ (temperature of expired air) to calculate $E$ and $\rho_{E}$, and to evaluate the constants in equations (4) and (5). Alternatively, the dependent variables $E$ and $\dot{V}$ (the most difficult variables to determine from laboratory experiments) can be calculated from the simultaneous solution of equations (1) and (3) if $\dot{m}_{R}$ also is known.

\section{(c) VOLUME CORRECTION COEFFICIENT}

The volume of expired air usually is less than the volume of inspired air. This occurs when the respiratory exchange ratio $\left(R=\dot{V} \mathrm{CO}_{2} / \dot{V} \mathrm{O}_{2}\right)$ is less than unity. We define a volume correction coefficient $(\alpha)$, as $\dot{V}_{I} / \dot{V}_{E}$, to be used in equations (1) and (C5) to account for differences in volumes of inspired and expired air that result from unequal quantities of oxygen 
consumption and carbon dioxide production. Otis (1964) has proposed that the ratio of expired to inspired nitrogen (a gas not exchanged by lungs) ". . . may be regarded as a correction factor for the shrinkage or expansion of $\dot{V}_{1}$ that occurs when the exchange of $\mathrm{CO}_{2}$ and $\mathrm{O}_{2}$ are unequal." Both of these definitions of $\alpha$ are identical.

Inclusion of the correction coefficient may be of greater conceptual than practical importance. For example, $\alpha$ calculated from data for the composition of respiratory gases of a resting human with $R=0.85$ (Kao, 1974, Table IV.2) is only 1.006. Thus, we suggest that the small size of the correction coefficient renders its effect on calculated values of respiratory water loss negligible relative to inevitable inaccuracies in physical and biological measurements required for equations (1) and (3).

Data required to evaluate the coefficient for the kangaroo rat are not contained in Collins et al. (1971); nor are we aware that the requisite data exist elsewhere. Thus, we have assumed that $\alpha=1$ in our calculations.

\section{(D) TEMPERATURE AND PRESSURE CONDITIONS OF RESPIRATORY VENTILATION}

The derivation of equation (1) in Appendix B necessitates that $\dot{V}, \dot{V}_{I}$ and $\dot{V}_{E}$ be expressed at the same temperature and pressure. During respiration, however, $\dot{V}_{I}$ is at ambient (inspired) temperature and has a water vapor pressure determined by the water vapor content of ambient air, while $\dot{V}_{E}$ is at the temperature of expired air and a water vapor pressure that is the saturation water vapor pressure at the temperature of expired air. In a strict sense, then, $\dot{V}_{I}$ and $\dot{V}_{E}$ do not occur at the same conditions.

The magnitude of the maximum difference between $\dot{V}_{I}$ and $\dot{V}_{E}$ due to temperature and pressure differences can be exemplified by a "worst case" situation. At an ambient temperature of $34.2^{\circ} \mathrm{C}$, kangaroo rats have a respiratory ventilation rate of $8.70 \times 10^{-3} \mathrm{~cm}^{3}$ air/ $(\mathrm{g} \cdot \mathrm{s})$ BTPS (Collins et al., 1971, Table II). If one assumes that inspired air is completely saturated with water vapor, the above ventilation rate expressed at inspired and expired conditions (from the ideal gas law) yields calculated values for $\dot{V}_{I}$ and $\dot{V}_{E}$ of $8.54 \times 10^{-3}$ and $8.65 \times 10^{-3} \mathrm{air} /(\mathrm{g} \cdot \mathrm{s})$, respectively. There is a difference of only $1.3 \%$ between $\dot{V}_{I}$ and $\dot{V}_{E}$ for this situation, and the magnitude of the difference is even less if the temperature and/or water vapor content of inspired air decreases.

The slight inequality between $\dot{V}_{I}$ and $\dot{V}_{E}$ due to temperature and pressure differences, of course, has a negligible effect on calculations of respiratory water loss. Therefore, we have assumed that the same conditions obtain for both inspiration and expiration and have expressed $\dot{V}$ in equations (1) and (3) as determined by ambient temperature and water vapor pressure. 
Included in equation (3) is a coefficient $(\beta)$ that converts $\dot{V}$ from ambient conditions to express oxygen consumption $\left(\dot{V} \mathrm{O}_{2}\right)$ at the requisite STPD (Kao, 1974).

\section{Model Behavior}

The respiratory water loss of a kangaroo rat in a laboratory situation can be demonstrated readily. If the rat is placed in a metabolic chamber with walls of high thermal emissivity, and the animal's heat losses due to evaporative heat transfer are small relative to all other modes of heat loss, the resting oxygen consumption of the animal in the chamber may be approximated as a simple function of air temperature (Tracy, 1972). (Natural environments, however, are rarely so simple. For example, convective heat exchange is usually a function of varying wind speed, and radiative heat transfer includes both solar and long wave infrared radiation.) Using this simplistic representation of oxygen consumption for resting kangaroo rats, we have calculated respiratory water loss from the simultaneous solution of equations (5), (4), (3) and (1). The results are graphically expressed as a function of air temperature, relative humidity and oxygen consumption in Fig. 4.

It is apparent that this animal simultaneously can minimize water and energy losses by seeking a moderately high temperature and humidity in

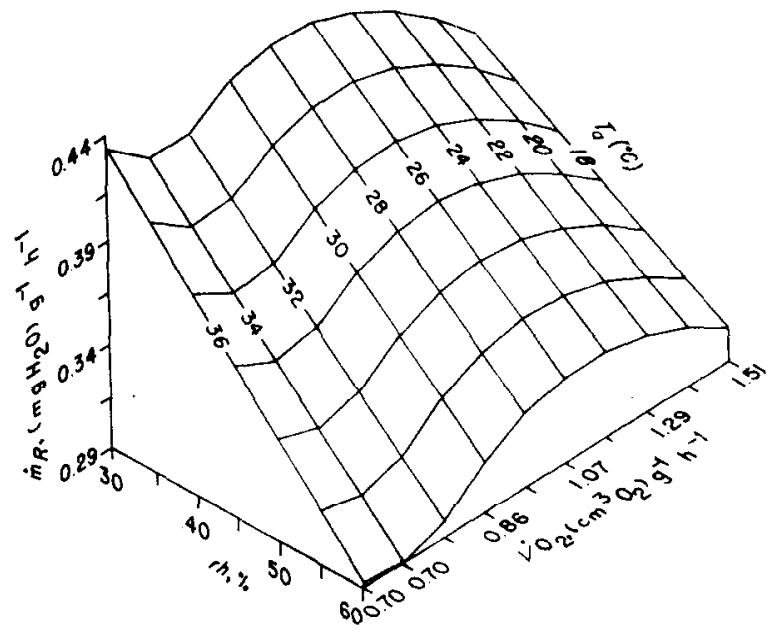

FIG. 4. Respiratory water loss $\left(\dot{m}_{R}\right)$ as a function of air temperature $\left(T_{a}\right)$, relative humidity $(r h)$, and oxygen consumption $\left(\dot{V O}_{2}\right)$ for the banner-tail kangaroo rat (Dipodomys spectabilis). Oxygen consumption $\left[\mathrm{cm}^{3} \mathrm{O}_{2} /(\mathrm{g} \cdot \mathrm{h})\right]$ was related to ambient (inspired) air temperature as $\dot{V} \mathrm{O}_{2}=0.70\left(33^{\circ} \mathrm{C}<T_{a}<36^{\circ} \mathrm{C}\right)$ and $\dot{V} \mathrm{O}_{2}=2.48-0.054 T_{a}\left(18^{\circ} \mathrm{C}<\right.$ $T_{a}<33^{\circ} \mathrm{C}$ ) using data from Collins et al. (1971, Table II). Respiratory water loss was calculated from equations (1), (3-5) using the regression coefficients in Figs 1 and 3. 
the environment. Further, it is interesting that a kangaroo rat in a humid environment can best conserve water at high environmental temperatures (low oxygen consumption); however, in an arid environment, the rat can conserve water best at high and low rather than intermediate ambient temperatures (or consequent oxygen consumption rates). This implies that in dry environments, rats could seek conditions that are expensive in terms of energy costs, and yet economical in terms of water losses.

It should be noted [from equations (1)-(3) and Fig. 4] that respiratory evaporation depends on a complex interaction of both organismal and environmental variables. In particular, relative humidity has a significant effect. This environmental variable, however, seldom is considered in laboratory studies of evaporative water loss [e.g. see Whittow (1971) for recent review relative to mammals].

\section{Model Applications}

Once the empirical relationship between the water vapor density of expired air and the temperature and humidity of inspired air, and the relationship between the oxygen extraction coefficient and oxygen consumption have been determined, respiratory water loss can be calculated readily from the temperature and relative humidity of the ambient air and the oxygen consumption of the organism. Since the metabolic rates (product of oxygen consumption and energy equivalent of oxygen) of animals often are direct responses to thermal environments, energy budget equations (Porter \& Gates, 1969; Tracy, 1972) can be used to predict the metabolic rates that are needed to calculate respiratory water loss. Respiratory evaporation, however, is a source of heat transfer, and, therefore, part of the energy balance. Thus, an energy budget equation must be solved simultaneously with equations (5), (4), (3) and (1). This simultaneous solution allows prediction of respiratory water loss solely in terms of the previously determined relationships (extraction coefficient versus oxygen consumption, and temperature and water vapor density of expired air versus inspired air), and the components of the physical environment entering into the energy budget of the organism (Porter \& Gates, 1969).

Respiratory evaporation, of course, is only one component of total evaporative water loss from animals. For resting kangaroo rats at $26^{\circ} \mathrm{C}$ and over a range of water vapor densities, respiratory and cutaneous evaporation constitute, respectively, about $84 \%$ and $16 \%$ of total evaporation (Chew \& Dammann, 1961); for active animals the percentage of respiratory evaporation may be even greater. 
Respiratory evaporation for active animals has not been studied extensively. Raab \& Schmidt-Nielsen (1972), however, have measured total evaporative water loss from running kangaroo rats. Unfortunately, sufficient data are not available from their study to evaluate the parameters in equation (4). The relationship between oxygen consumption and extraction coefficient for exercising animals is entirely unknown, and Raab \& SchmidtNielsen (1972) point to the difficulty of measuring oxygen extraction coefficient for kangaroo rats. As indicated above, given the appropriate data, calculation of the extraction coefficient is readily accomplished with the model we have presented. Raab \& Schmidt-Nielsen (1972) also suggest the possible influence of higher respiratory ventilation during activity on the temperature of expired air (and thus on $\rho_{E}$ ). Their measurements were made over a range of air temperatures, but only in dry air; thus evaluation of the parameters in equation (5) is not possible from their data.

In its present form the model has limited applicability for calculating respiratory water loss from active animals in thermally and hygrically complex environments. It is very difficult, for example, to accurately estimate the oxygen consumption of active animals in their natural habitats. Within the restrictions of presently available data, we have exemplified evaluation of the model parameters for resting kangaroo rats in a laboratory environment. Nevertheless, because the model is based on physical and physiological mechanisms that determine respiratory evaporation, the general relationships expressed by the model should be valid for animals under any naturally occurring situation. It is necessary only to evaluate the model parameters for a more realistic range of physical and behavioral conditions than has been done to date. Thus, we feel that the model points to present shortcomings in understanding of the interrelationships among respiratory processes, and that it provides a framework for future modeling of respiratory water loss.

We are grateful to B. A. Wunder for helpful suggestions on an earlier version of the manuscript. The derivation of equation (3) was developed, in part, by one of the anonymous reviewers. A. Chambers, D. Chandler, C. Hughes, A. Jabusch and $\mathrm{K}$. Maxwell assisted on the technical preparation of this paper. This work was partially supported by N.S.F. Grants GB-31043 and BMS 74-19454 to W. P. Porter and J. W. Mitchell, and a Faculty Research Grant to C. R. Tracy.

\section{REFERENCES}

Bernstein, M. H. \& Schmidt-Nielson, K. (1974). Resp. Physiol. 21, 393.

Chew, R. M. \& Dammann, A. E. (1961). Science, N.Y. 133, 384.

Collins, J. C., Pilkington, T. C. \& Schmidt-Nielsen, K. (1971). Biophy's. J. 11, 886.

Getz, L. L. (1968). Comp. Biochem. Physiol. 24, 335.

Hulbert, A. J. \& Dawson, T. J. (1974). Comp. Biochem. Physiol. 47A, 591. 
Jackson, D. C. \& Schmidt-Nielsen, K. (1964). Proc. natn. Acad. Sci. U.S.A. 51, 1192.

JoYCE, J. P. \& BlaXter, K. L. (1964). Res. Vet. Sci. 5, 505.

KAO, F. F. (1974). An Introduction to Respiratory Physiology. New York: American Elsevier Publ. Co.

McCutchan, J. W. \& Taylor, C. L. (1951). J. Appl. Physiol. 4, 121.

MURRISH, D. E. (1973). Resp. Physiol. 19, 262.

MURrish, D. E. \& Schmidt-Nielsen, K. (1970). Resp. Physiol. 10, 151.

OTIs, A. B. (1964). In Handbook of Physiology. Sect. 3: Respiration, Vol. 1, p. 681.

Washington: Am. Physiol. Soc.

Porter, W. P. \& GATES, D. M. (1969). Ecol. Monogr. 39, 227.

RAAB, J. L. \& Schmidt-Nielsen, K. (1972). Am. J. Physiol. 222, 1230.

SCHMIDT-NielseN, K. (1972). How Animals Work. London: Cambridge University Press.

Schmidt-Nielsen, K., Hainsworth, F. R. \& Murrish, D. E. (1970). Resp. Physiol. 9, 263.

Seymour, R. S. (1972). I. theor. Biol. 35, 119.

TAYLOR, C. R. (1969). Am. J. Physiol. 217, 317.

TraCY, C. R. (1972). Bioscience 22, 656 (erratum, 23, 296).

WhITTOw, G. C. (1971). Comparative Physiology of Thermoregulation, Vol. 2. New York: Academic Press.

\section{APPENDIX A}

\section{Nomenclature}

\begin{tabular}{|c|c|c|}
\hline Symbol & Quantity & Units \\
\hline$E$ & $\begin{array}{l}\text { oxygen extraction coefficient, } \\
\qquad\left[F_{I} \mathrm{O}_{2}-\left(F_{E} \mathrm{O}_{2} / \alpha\right)\right] / F_{I} \mathrm{O}_{2}\end{array}$ & non-dimensional \\
\hline$f$ & respiratory frequency & breaths/min \\
\hline$F_{E} \mathrm{~N}_{2}$ & fraction of nitrogen in expired air & $\mathrm{m}^{3} \mathrm{~N}_{2} / \mathrm{m}^{3}$ air \\
\hline$F_{E} \mathrm{O}_{2}$ & fraction of oxygen in expired air & $\mathrm{m}^{3} \mathrm{O}_{2} / \mathrm{m}^{3}$ air \\
\hline$F_{1} \mathrm{~N}_{2}$ & fraction of nitrogen in inspired air & $\mathrm{m}^{3} \mathrm{~N}_{2} / \mathrm{m}^{3}$ air \\
\hline $\begin{array}{l}F_{1} \mathrm{O}_{2} \\
k_{n}\end{array}$ & $\begin{array}{l}\text { fraction of oxygen in inspired air } \\
\text { constant resulting from regression analysis }\end{array}$ & $\begin{array}{l}\mathrm{m}^{3} \mathrm{O}_{2} / \mathrm{m}^{3} \text { air } \\
\text { (various) }\end{array}$ \\
\hline$m$ & body mass & $\mathrm{g}$ \\
\hline$\dot{m}_{E}$ & water lost during expiration & $\mathrm{g} \mathrm{H}_{2} \mathrm{O} /(\mathrm{g} \cdot \mathrm{min})$ \\
\hline$\dot{m}_{1}$ & water gained during inspiration & $\mathrm{g} \mathrm{H}_{2} \mathrm{O} /(\mathrm{g} \cdot \mathrm{min})$ \\
\hline$\dot{m}_{R}$ & respiratory water loss & $\mathrm{g} \mathrm{H}_{2} \mathrm{O} /(\mathrm{g} \cdot \mathrm{min})$ \\
\hline$R$ & respiratory exchange ratio, $\dot{V} \mathrm{CO}_{2} / \dot{V} \mathrm{O}_{2}$ & non-dimensional \\
\hline$T_{I}$ & temperature of inspired (ambient) air & ${ }^{\circ} \mathrm{C}$ \\
\hline$V_{T}$ & respiratory tidal volume & $\mathrm{m}^{3}$ air/breath \\
\hline$\dot{V}$ & respiratory ventilation, $\dot{V}=\dot{V}_{I}=\alpha \dot{V}_{E}$ & $\mathrm{~m}^{3}$ air $/(\mathrm{g} \cdot \mathrm{min})$ \\
\hline$\dot{V}_{E}$ & volume flow of expired air & $\mathrm{m}^{3}$ air $/(\mathrm{g} \cdot \mathrm{min})$ \\
\hline & volume flow of inspired air & $\mathrm{m}^{3}$ air $/(\mathrm{g} \cdot \mathrm{min})$ \\
\hline $\begin{array}{l}\dot{\mathrm{V}} \mathrm{CO}_{2} \\
\dot{\mathrm{V}} \mathrm{O}_{2}\end{array}$ & $\begin{array}{l}\text { carbon dioxide production } \\
\text { oxygen consumption }\end{array}$ & $\begin{array}{l}\mathrm{m}^{3} \mathrm{CO}_{2} /(g \cdot \min ) \text { STPD } \\
\mathrm{m}^{3} \mathrm{O}_{2} /(\mathrm{g} \cdot \min ) \text { STPD }\end{array}$ \\
\hline
\end{tabular}


$\alpha \quad$ volume correction coefficient for expired non-dimensional air, $F_{E} \mathrm{~N}_{2} / F_{I} \mathrm{~N}_{2}$

$\beta \quad$ coefficient to convert $\dot{V}$ from ambient to non-dimensional STPD conditions

$\rho_{E} \quad$ water vapor density of expired air

$\rho_{I} \quad$ water vapor density of inspired air

$\mathrm{g} \mathrm{H}_{2} \mathrm{O} / \mathrm{m}^{3}$ air

$\mathrm{g} \mathrm{H}_{2} \mathrm{O} / \mathrm{m}^{3}$ air

\section{APPENDIX B}

\section{Derivation of Equation (1)}

Respiratory water loss can be expressed as the net exchange between water lost during expiration and water gained during inspiration so that

$$
\dot{m}_{R}=\dot{m}_{E}-\dot{m}_{I} \text {. }
$$

Physiological and physical variables are substituted in equation (B1) to yield

$$
\dot{m}_{R}=\left(\dot{V}_{E} \rho_{E}\right)-\left(\dot{V}_{I} \rho_{I}\right)
$$

The respiratory exchange ratio $\left(R=\dot{V} \mathrm{CO}_{2} / \dot{V} \mathrm{O}_{2}\right)$ accounts for the decrease or increase in the volume of expired air; only when $R=1$ will $\dot{V}_{E}=\dot{V}_{I}$. The magnitude of change is expressed by

$$
\dot{V}_{I}=\left(F_{E} \mathrm{~N}_{2} / F_{I} \mathrm{~N}_{2}\right) \dot{V}_{E}
$$

[See Otis (1964) for derivation and discussion of equation (B3).] Respiratory ventilation and the volume correction coefficient $(\alpha)$ from equation (B3) are defined to obtain

$$
\dot{V}=\dot{V}_{I}=\alpha \dot{V}_{E}
$$

Substitutions from equation (B4) are made in equation (B2) to yield

or

$$
\dot{m}_{R}=\left[(\dot{V} / \alpha) \rho_{E}\right]-\left(\dot{V} \rho_{I}\right)
$$

$$
\dot{m}_{R}=\dot{V}\left[\left(\rho_{E} / \alpha\right)-\rho_{I}\right] \text {. }
$$

\section{APPENDIX C}

\section{Derivation of Equation (3)}

Equation (3) is derived from the steady-state Fick equation for oxygen consumption (Kao, 1974)

$$
\dot{V} \mathrm{O}_{2}=\left(\dot{V}_{I} F_{1} \mathrm{O}_{2}\right)-\left(\dot{V}_{E} F_{E} \mathrm{O}_{2}\right)
$$


Substitutions from equation (B4) in equation (C1) yield

$$
\dot{V} \mathrm{O}_{2}=\left(\dot{V} F_{I} \mathrm{O}_{2}\right)-\left[(\dot{V} / \alpha) F_{E} \mathrm{O}_{2}\right] \text {, }
$$

or

$$
\dot{V} \mathrm{O}_{2}=\dot{V}\left[F_{1} \mathrm{O}_{2}-\left(F_{E} \mathrm{O}_{2} / \alpha\right)\right] \text {. }
$$

The coefficient $(\beta)$ to convert $\dot{V}$ from ambient to STPD conditions is introduced to yield

$$
\dot{V} \mathrm{O}_{2}=\beta \dot{V}\left[F_{I} \mathrm{O}_{2}-\left(F_{E} \mathrm{O}_{2} / \alpha\right)\right] \text {. }
$$

Equation (C4) is divided by $F_{1} \mathrm{O}_{2}$ and the oxygen extraction coefficient (fraction of oxygen removed from inspired air) is defined as

to yield

$$
E=\left[F_{1} \mathrm{O}_{2}-\left(F_{E} \mathrm{O}_{2} / \alpha\right)\right] / F_{I} \mathrm{O}_{2}
$$

$$
\dot{V} \mathrm{O}_{2}=\beta \dot{V} E F_{1} \mathrm{O}_{2}
$$

or

$$
\dot{V}=\dot{V} \mathrm{O}_{2} /\left(\beta E F_{1} \mathrm{O}_{2}\right) \text {. }
$$

